\title{
Telling stories to communicate the value of the pre-employment structured job interview
}

\author{
Don C. Zhang, Xiaoyuan (Susan) Zhu, Kelsey-Jo Ritter \& Aneeqa Thiele
}

\begin{abstract}
Author Note
Corresponding concerning this study should be sent to Don Zhang at zhang1@1su.edu.

Don C. Zhang, PhD, Department of Psychology, Louisiana State University, Baton Rouge, LA

Xiaoyuan (Susan) Zhu, PhD, Society for Human Resource Management, Alexandria, VA

Kelsey-Jo Ritter, PhD, Manchester University, Department of Psychology, Fort Wayne, IN

Aneeqa Thiele, Department of Psychology, Louisiana State University
\end{abstract}

\section{Version Note}

Final draft of the manuscript has been accepted in International Journal of Selection and Assessment. This version is not the copy of record and may not exactly replicate the final, authoritative version of the article. 


\begin{abstract}
In an effort to bridge the scientist-practitioner gap in employee selection, some researchers have advocated telling stories to better communicate the value of evidence-based hiring practices to human resource (HR) professionals. In this paper, we conducted two experiments that examine the efficacy of storytelling for overcoming managers' resistance to using structured job interviews. In two experiments, we found that participants who read a story regarding the effectiveness of structured interviews, as opposed to receiving evidence-based advice, reported more favorable attitudes toward structured job interviews. Serial mediation analysis revealed that the observed attitude change was mediated by an increase in narrative transportation and reduction in counterarguing. Implications for using stories in communicating the value of evidence-based HR practices are discussed.
\end{abstract}

Keywords: structured interview; narrative persuasion; science communication; employee selection; evidence-based management (EBMgt); storytelling; attitude change 
"The power of storytelling is exactly this: to bridge the gaps where everything else has crumbled." - Paulo Coelho, Award-winning novelist, author of The Alchemist

Across time and cultures, people told parables — stories with a lesson — to instill socially responsible behaviors. The popular book and motion picture, Moneyball, told the story of the Oakland Athletics baseball manager Billy Beane, who pioneered data-driven methods and transformed the assessment of professional baseball players - a field previously dominated by intuition and subjectivity (Lewis, 2004). Similarly, employment selection scholars have long grappled with managers' overreliance on intuitive and subjective methods of interviewing in favor of structured job interviews, which are more reliable, valid and equitable (Highhouse, 2008; Kausel, Culbertson, \& Madrid, 2016; Roulin \& Bangerter, 2012; S. L. Rynes, Colbert, \& O’Boyle, 2018; Van der Zee, Bakker, \& Bakker, 2002). Indeed, the gap between science and practice in employee selection research remains one of "intractable" challenges of workplace psychology and human resources management (Ryan \& Ployhart, 2014, p.695).

To date, prescriptions for overcoming managers' resistance toward evidence-based hiring practices have primarily focused on more efficient ways to communicate statistical validity evidence (e.g., Highhouse, Brooks, Nesnidol, \& Sim, 2017; Zhang, Highhouse, Brooks, \& Zhang, 2018). Statistical evidence, however, is not the only tool for persuasion. Lievens and De Paepe (2004) advised practitioners to "go beyond a lecture with presentations of validity evidence" (p.42). Research from the communication literature suggests that a well-crafted story can be more persuasive than fact- or reason-based advice (Bilandzic \& Busselle, 2013; Dahlstrom, 2014; Green \& Brock, 2000). Whereas empirical evidence and reasoning may activate reactance and reinforce the audience's existing position on a topic (Petty, Tormala, \& 
Rucker, 2004), stories can sidestep such resistance, and thereby, enhance persuasion (MoyerGusé, 2008). Storytelling is particularly useful when the target audience holds contrary beliefs, such as attitudes toward using the structured job interview during the selection process.

In the present paper, we examined the efficacy of storytelling for overcoming managers' resistance to the structured interview. We chose to focus on the structured job interview because, despite a great deal of empirical evidence supporting its effectiveness in the selection process, human resource professionals continue to rely on intuition-based interview methods (Fernandez \& Pougnet, 2018; Lievens \& De Paepe, 2004; Tsai, HsinHung Chen, Chen, \& Tseng, 2016; Van der Zee et al., 2002). In Study 1, using a general adult sample, we examined the persuasive benefits of storytelling over rational advice for communicating the value of structured interviews. We also examined the degree to which knowledge of the storyteller's background may affect the persuasion process. In Study 2, we extended our results by examining - using a pretest-posttest design - the efficacy of storytelling for changing managers' intentions toward using the structured job interview. Using a combination of statistical and experimental methods, we also shed light on the psychological mechanisms of narrative persuasion. Our paper answers the call for using stories and anecdotes to communicate the value of evidence-based hiring practices (Kuncel, 2008; Lievens \& De Paepe, 2004; Rynes, 2009). We contribute to employee selection research and practice by demonstrating that storytelling can serve an important role in encouraging HR professionals to adopt evidence-based hiring practices such as structured job interviews.

\section{Background}


Evidence-based HR practices have been shown to improve company profits, work efficiency, and employee performance (Moore, 2017; Rynes \& Bartunek, 2017). The structured job interview, in particular, has received considerable attention as an effective pre-employment assessment method (Levashina, Hartwell, Morgeson, \& Campion, 2014). However, structured interviewing continues to be resisted by managers (Dana, Dawes, \& Peterson, 2013; Fernandez \& Pougnet, 2018; Lievens \& De Paepe, 2004). For instance, Nolan and colleagues (2016) found that managers feel that their sense of job-related competence is threatened if they use structured interviews. Instead, managers often prefer unstructured interviews (i.e., interviews without a specified set of questions) to exercise their autonomy, discretion, and power over the hiring process (Highhouse, Nye, \& Zhang, 2018; Lievens \& De Paepe, 2004). Many managers find the structured interview too rigid or simply not useful (Chen, Tsai, and Hu, 2008; Terpstra and Rozell, 1997). Nevertheless, research consistently shows that increasing the use of structured interview could significantly enhance hiring outcomes (Huffcutt \& Arthur, 1994; Lubbe \& Nitsche, 2019) and reduce adverse impact (Huffcutt \& Roth, 1998; Williamson, Campion, \& Malos, 1997). Indeed, a bad hire can incur a significant financial cost (Forbes, 2016) have a negative impact on workplace morale and productivity (Dunlop \& Lee, 2004)

Efforts to combat such resistance have primarily focused on more effective means of presenting statistical evidence (Highhouse et al., 2017; Zhang et al., 2018) or using alternative numerical metrics such as utility analysis (Macan \& Highhouse, 1994) to better communicate the value of evidence-based practices to relevant stakeholders. Zhang and colleagues (2018), for example, found that managers were more willing to adopt structured interviews when validity information was presented using alternative graphical displays. The persuasive capacity of 
statistical evidence, however, may be limited: many managers are not sufficiently trained in statistics or fluent in numerical comprehension (Best, 2001; Kirsch, Jungeblut, Jenkins, \& Kolstad, 2002). The use of statistics alone may even backfire. When faced with statistical evidence, opponents of evidence-based hiring methods may engage in motivated reasoning by summoning anecdotal evidence to support their position: easily remembering the one person who succeeded at school or work despite a tests' predictions (Rynes et al., 2018). Relatedly, Caprar, Do, Rynes, and Bartunek (2016) found that management students are more likely to reject validity evidence that threatens their self-concept. Indeed, Bartunek (2007) cautioned that simply revealing a gap between research and practice by presenting empirical evidence may engender resistance, rather than motivation to change.

\section{Storytelling as a Tool for Persuasion}

Stories, or narratives, are defined as "a structured, coherent retelling of an experience or a fictional account of an experience" (Schank \& Berman, 2002). We operationalize a persuasive story as a passage with the following characteristics: 1) it contains a linear progression of events and actions; 2) it is told from the perspective of a character in the story; and 3) it concludes with a resolution, which describes an outcome to the main character as a result of his or her actions (i.e., moral of the story). Narrative persuasion, therefore, uses a story to communicate an underlying persuasive message (Bilandzic \& Busselle, 2013). Non-narrative persuasion, in contrast, involves putting forth advice or suggestions supported by empirical data and logically related arguments. Most "practical implications" sections of scientific articles, for example, are presented in this format: advice is given based on theory and data. 
Researchers from various disciplines have used storytelling to promote beneficial behaviors in safety, health, and financial domains (See Braddock \& Dillard, 2016, for review). For example, stories in the form of testimonials have been used to improve the adoption of lifesaving public health programs (Hinyard \& Kreuter, 2006); similarly, imagery-rich stories are used to promote safe workplace behaviors (Ricketts, Shanteau, McSpadden, \& FernandezMedina, 2010). In a field experiment, door-to-door canvassers significantly reduced transphobia in the general public by sharing their stories of transgender experiences (Broockman \& Kalla, 2016). Stories are particularly useful when the target audience holds contrary beliefs (Wojcieszak \& Kim, 2016). Indeed, a good story may overcome entrenched beliefs, such as the managers' reliance on intuition-based assessment methods (e.g., unstructured interviews; Highhouse, 2008).

Overcoming resistance with stories. Resistance to a message is activated when the target audience detects a persuasive intent (Knowles \& Linn, 2004). In particular, resistance is magnified when the message contradicts the target audience's prior beliefs (Petty et al., 2004). One manifestation of resistance is counterarguing, which is the "generation of thoughts that dispute or are inconsistent with the persuasive argument" (Slater \& Rouner, 2002, p108). Many human resource professionals believe that research evidence does not apply to their unique situations where human experts are required to interpret the configuration of traits of individual candidates (Highhouse, 2008). Therefore, simply providing evidence of the effectiveness of structured interviews may elicit more counterarguments and strengthen people's existing contrary beliefs, rather than changing them. 
Storytelling can overcome these limitations of evidence-based advice or rational reasoning because stories can mask persuasive intent of the message (Moyer-Gusé, 2008). Based on transportation theory (Green \& Brock, 2000), stories direct the reader's focus to the characters and their experiences in the story by "transporting" them to the narrative world. When watching Lord of the Rings, for instance, the viewer accepts fictitious concepts - such as magic and dragons - to be true (Green, Brock, \& Kaufman, 2004; Slater \& Rouner, 2002b). In other words, once the audiences' focus is shifted to the experiences of the characters in a story, their motivation to scrutinize persuasive content is suppressed. Moreover, because the characters in a story are not directly authoritative or controlling, the audience is less resistant to the persuasiveness of the content (Moyer-Gusé \& Nabi, 2010). In contrast, non-narrative advice makes factual statements and appeals to people's logic, which makes it more susceptible to being refuted. In sum, people will be less likely to argue against the message content when it is provided in a narrative format because it focuses on the experiences of characters in the story, rather than explicitly advocating for a position. Given the ability of narratives to reduce resistance, we expect people to counterargue less after reading a story about the effectiveness of structured interviews than after reading non-narrative advice:

Hypothesis 1. Participants will report less counterarguing when reading a story vs. nonnarrative advice.

Decision-making researchers have shown that the process of gathering evidence influences people's subsequent strength of attitudes and preferences (Ratcliff \& Smith, 2004). Others have theorized that the reduction in counterarguing is a primary causal mechanism for inducing story-consistent beliefs (Bilandzic \& Busselle, 2013). As people come up with more 
reasons against the value of structured interviews, their subsequent attitudes should be less favorable. Therefore, via a reduction in counterarguing as a mediator, we hypothesize that people who read a story will report more favorable attitudes toward structured interviews:

Hypothesis 2. Participants will report more favorable attitudes toward the structured job interview when reading a story vs. non-narrative advice.

Hypothesis 3. Counterarguing will mediate the relationship between message content type (story vs. non-narrative advice) and attitudes toward structured interviews.

Causal effects of counterarguing on attitude change. The theoretical model assumes that counterarguing has a causal impact on subsequent attitudes. Reversal causality effects, however, are also plausible. From a motivated reasoning perspective, people selectively seek information and rationales on the basis of their underlying attitudes and beliefs (Kunda, 1990). Therefore, it is plausible that the act of counterarguing does not cause a change in people's subsequent attitudes, but rather, people who already feel positively (negatively) about structured interviews are less (more) motivated to come up with counterarguments. The direction of the causal inference, however, cannot be fully tested in a mediation model alone.

Pearl and Mackenzie (2018) argued that in order for one variable (e.g., temperature) to have a causal effect on another (e.g., thermometer level), the outcome variable must "listen" to the causal variable whereby changes in the causal variable produce change in the outcome variable at a later time. Therefore, the temporal ordering between counterarguing and subsequent attitudes matters for establishing causality. Furthermore, it is important to examine the counterfactual to rule out reverse causality effects. In other words, to fully establish causality, one also 
has to experimentally demonstrate that - in the absence of the change in the causal variable there would be no change in the outcome variable.

In this study, we experimentally manipulated the temporal order of counterarguing relative to people's report of their attitude. If the act of counterarguing indeed causes a change in subsequent attitudes, we would expect that people who engaged in counterarguing prior to reporting their attitudes to have less favorable attitudes for the structured interview than those who did not engage in counterarguing. Put it another way, the precise causal effect of counterarguing on subsequent attitudes is reflected in the differences in people's attitudes toward the structured interview between those who engaged in counterarguing vs. those who did not. Experimentally manipulating the engagement of counterarguing, therefore, provides the strongest possible test for establishing causality. Therefore, we hypothesize:

Hypothesis 4. Participants will report more favorable attitudes toward the structured interview if they engaged in counterarguing prior (vs. after) to revealing their attitudes.

Character background. Stories often provide detailed information about the characters to enhance the realism of the story (Green \& Brock, 2000), thus enhancing their believability. Characters with rich background information tend to be more relatable (Johnson, Hashtroudi, \& Lindsay, 1993). Moreover, past research has found that the persuasiveness of character is strengthened when the target audience feels a strong sense of identification with a character, which can be elicited by providing the audience with meaningful background information (de Graaf, Hoeken, Sanders, \& Beentjes, 2012; Moyer-Gusé, Chung, \& Jain, 2011). Although a rich character background may strengthen the believability of a narrative story, this effect may not apply to non-narrative advice. Based on transportation theory, the audience may not be engaged 
in creating a mental model of a narrative world constructed by the protagonist when reading nonnarrative advice, thus negating the benefits of a rich background. Therefore, we expect that detailed character background information will be most beneficial for narrative persuasion.

Hypothesis 5. Character background will moderate the effect of content on narrative persuasion. An enriched, as opposed to impoverished character background will strengthen the persuasive effects of a story, but not advice.

\section{Study 1}

The main purpose of Study 1 was to examine the effects of storytelling on people's subsequent attitudes toward the structured interview and the role of counterarguing as a mediator. Participants in this study were instructed to read a script of a hypothetical conversation where a psychology graduate answered some questions about their work experience as an organizational consultant. The instructions were kept ambiguous to obscure the true purpose of the study, which could elicit reactance and experimenter demand effects (Cheung, Burns, Sinclair, \& Sliter, 2016). To enhance the realism and ecological validity of the interview script, alumni of an Industrial-Organizational Psychology doctoral program in the United States answered the background questions for the conversation based on her personal experiences. The content of the script contained either a story of a consulting project in which a structured interview was used or general advice on how to conduct a structured job interview. The narrative story was based on a real consulting project conducted by students of the doctoral program. Based on suggestions to maximize generalizability (Highhouse, 2009), we also varied the details in the stimulus (e.g., name, alma mater of the consultant, name of company) to introduce stimulus variation. This ensured that extraneous details in the script (e.g., gender, recognition of 
school) did not influence the observed effects. Details of the script are presented in the following section.

\section{Study 1: Method}

\section{Sample}

Two hundred and seventy-six MTurk workers from the United States were paid 75 cents to participate. Given the relatively novel nature of this research and that a controlled experimental design was utilized, MTurk served as an adequate platform to address our research questions (Zhu, Barnes-Farrell, \& Dalal, 2015). Participants were removed from the dataset for either failing the attention check question (e.g., "please respond to this question with strongly disagree") or missing two of the three multiple-choice comprehension check questions to ensure that they read the script, (e.g., "the graduate is currently working as...”). This resulted in a final sample of 253 participants (Mean age $=36 ; 50 \%$ male; $83 \%$ Caucasian; $82 \%$ employed full or part-time). Seventy-three percent of the participants reported that they had conducted job interviews in their career: 39 percent indicated that they had conducted more than five job interviews in their career.

\section{Script Development}

Both the story and advice versions of the script described the main characteristics of structured interviews and why they are resisted. In the story condition, the main character described a personal experience in which they developed a structured interview system for a company. Throughout the story, the main character does not explicitly state that a structured interview was superior, nor that the structured interview was more predictive of job performance. Rather, the story concludes with a "resolution," that is, the character describes the positive 
outcome associated with the adoption of the structured interview. Alternatively, in the advice condition, the main character clearly recommends using a structured interview, outlines the advantages of the structured interview, and states that the structured interview is more predictive of job performance (Appendix A) ${ }^{1}$. Moreover, we also varied the amount of background information (enriched vs. impoverished) for the character in the script (Appendix B). In the enriched condition, the main content of the script was prefaced with the main character talking about his or her personal interests and day-to-day duties on the job. In the impoverished condition, the main character only described his or her profession, with no additional information.

\section{Procedure}

We used a 2 (message content: story vs. advice) x 2 (character background: enriched vs. impoverished) x 2 (counterarguing order: before vs. after) between-subject experimental design. Participants were randomly assigned to different levels of the independent variables. Participants first read the script of the conversation, which included either an enriched or impoverished description of the character's background. Next, they read either the story or advice version of the script. Finally, participants were either instructed to counterargue against the value of structured interviews before (vs. after) indicating their attitudes. Counterarguing was elicited by asking the participants to "list as many reasons against using the structured interview in assessing job candidates as possible." This is a standard method of eliciting counterarguments and for

\footnotetext{
${ }^{1}$ The story and advice scripts each scored an 8 and 9 on the Flesch-Kincaid Grade Level readability scale (calculated with readability-score.com), which indicates that both scripts were written at no higher than a high school reading level. Stories also had similar word count (323 vs. 367 ); word per sentence (20 vs. 18); and number of 6-letter or more words ( $22 \%$ vs. $20 \%$ ).
} 
measuring psychological resistance in the persuasion literature (Bilandzic \& Busselle, 2013;

Kopfman, Smith, Ah Yun, \& Hodges, 1998; Moyer-Gusé \& Nabi, 2010).

\section{Measures}

Attitudes toward the structured interview. A four-item scale was developed to measure people's attitudes toward the structured interview. As mentioned before, the detection of the persuasive intent may trigger reactance. Therefore, the items were written to be as neutral as possible. The items were: 1) "Interview questions should be consistent across job candidates for the same job"; 2) "The best way to conduct a job interview is to have questions prepared beforehand rather than coming up with them on the spot"; 3) "Each job candidate should be treated differently during a job interview"; and 4) "Job interviews should be free-flowing rather than structured". The scale had good reliability (Cronbach's $\alpha=0.85)$.

Counterarguing. In order to triangulate on the process of counterarguing and reduce common method variance (Podsakoff, MacKenzie, Lee, \& Podsakoff, 2003), we used multiple indicators of counterarguing behavior. First, Computerized Text Analysis was used to examine the content of the argument; second, participants reported on their engagement in counterarguing. We will discuss each method in turn.

Tentativeness. We used the Linguistic Inquiry Word Count (LIWC, Pennebaker, Francis, \& Booth, 2001) software to examine the contents of the argument. The LIWC analyzes the words used in the thought-listing task and codes the responses based on a pre-defined dictionary where different words are assigned a category (see Tausczik \& Pennebaker, 2010, for more details). For the purpose of the present study, we focused on the category of tentativeness. Tentativeness was chosen as an indicator of the degree of uncertainty and confidence in the 
counterargument and was assessed by the proportion of words in the response that contain words such as "maybe, perhaps, guess.” An example of a counterargument with low tentativeness is: "intimidating to persons who get interviewed, hard to form new ideas, not a good idea"; whereas an example of a counterargument with high tentativeness is: "The employees would feel uncomfortable. It might not be the best for selecting the right people. It might disqualify competent people."

Reported counterarguing. The second method asked participants to report the degree to which they engaged in counterarguing (Moyer-Gusé, Chung, \& Jain, 2011). We used a threeitem self-report measure to assess counterarguing adapted from Moyer-Gusé et al., (2011) for the context of the present study. Participants were asked to think about the thought-listing task and respond to the following items: 1) "It was easy to come up with reasons against the structured interview"; 2) "There are many flaws in the argument that structured interviews are better", and 3) "The benefits of the structured interview are not well-supported." The counterarguing scale had good reliability (Cronbach's $\alpha=0.80$ ). We found a negative correlation between selfreported counterarguing and tentativeness $(\mathrm{r}=-.12, \mathrm{p}=0.05)$. The direction of the relationship suggested that people who self-reported more counterarguing were less tentative in their language use.

We used parallel analysis (Hayton, Allen, \& Scarpello, 2004) to determine the number of factors that best represented the items created for this study ${ }^{2}$. It has been suggested that Parallel

\footnotetext{
${ }^{2}$ Parallel analysis generates simulated data based on the sample size and number of variables in the data. Next, average eigenvalues from the simulated data are compared to the observed eigenvalues. Factors are retained when the observed eigenvalues are equal to or greater than the simulated eigenvalues.
} 
analysis has been shown to be among the most accurate methods for factor retention, compared to other procedures such as the maximum likelihood estimation (Humphreys \& Montanelli Jr, 1975 ) and the Kaiser criterion (Kaiser, 1960). Parallel analysis for the self-report measures of structured interview attitudes and counterarguing revealed two factors (Table 1)

\section{Study 1: Results and Discussion}

Table 2 contains the means, standard deviations, and intercorrelation of Study 1's variables. Hypothesis 1, 2, 4, and 5 were tested using analysis of variance (ANOVA). There was a main effect of message content on perceived counterarguing, $F(1,245)=8.71, p=.003$. People who read the story reported less counterarguing than people who read the advice, Cohen's $d=$ 0.39. There was also a main effect of message content on the tentativeness of the counterargument, $F(1,245)=5.98, p=.015$. People who read the story were more tentative in their counterarguments than those who read the advice, Cohen's $d=.26$; Hypothesis 1 was fully supported. There was no main effect of message content on people's attitudes toward the structured interview, $F(1,245)=.79, p=.38$; Hypothesis 2 was not supported. There was a significant main effect of counterargue order on the attitudes toward the structured interview, $F(1,245)=31.83, p<.001$. People who counterargued first indicated less favorable attitudes toward the structured interview than those who did not, Cohen's $d=.64$; Hypothesis 4 was supported. There was no significant interaction between message content and background richness on interview attitudes, $F(1,245)=0.16, p=.69$; Hypothesis 5 was not supported. All other interactions failed to reach statistical significance. Table 3 contains the means and standard deviations for the study's main outcome variables across conditions.

Mediation analysis. Mediation analyses were conducted using the lavaan package in R. 
Indirect effects were tested with 10,000 bootstrapping samples with bias-corrected confidence intervals (CIs). Participants in the story condition reported less counterarguing than those in the advice condition, and those with lower perceived counterarguing reported more favorable attitudes toward the structured interview. Table 4 contains the bootstrapped estimates of the indirect effects. The $95 \%$ confidence interval did not contain 0 , which indicated that the indirect effect was statistically significant (Shrout \& Bolger, 2002). Moreover, the story content (story vs. advice) had no direct effect on people's attitudes toward the structured interview independent of its effect on counterarguing. Therefore Hypothesis 3 was supported.

As predicted, people who read the story reported lower counterarguing than those who read the advice. And, people who reported lower counterarguing indicated more favorable attitudes toward the structured interview. We also experimentally verified - by randomly altering the order of participants' responses - that counterarguing had a causal effect on subsequent attitudes. In sum, Study 1 showed that when people read a story, they engaged in less counterarguing, and as a result, reported more favorable attitudes toward the structured interview.

Study 1 had several limitations. First, participants were asked explicitly to think of reasons against arguments made in the persuasive script. Although this procedure was required to examine the causal ordering of counterarguing and story-consistent aptitudes, it may have artificially weakened the persuasive effects of the scripts. The engagement of counterarguing, however, is an automatic response that occurs whenever a persuasive intent is detected. And it can occur with or without explicit instructions (e.g., Moyer-Gusé \& Nabi, 2010). Therefore, in the second study, we do not prompt participants to actively engage in generating 
counterarguments. In doing so, their report of counterarguing is more ecologically valid with respect to their automatic response to the persuasive attempt.

Second, the dependent variables were developed with the intention of not revealing the underlying purpose of the study, which was to persuade the readers to adopt more favorable views toward the structured interview. As a result, the items did not explicitly measure whether or not the message receiver is willing to change their behavioral intentions toward the structured interview, thus potentially undermining the practical significance of the findings. Finally, this specific sample of adults may not be personally invested in how job interviews ought to be conducted. Therefore, it is important to replicate the findings in a sample of managers who regularly conduct job interviews. The second experiment was conducted to remedy these limitations.

\section{Study 2}

Although Study 1 showed that narrative is more persuasive than advice, unclear is its persuasive efficacy compared to statistical evidence. Despite the objective nature of statistical evidence, the receiver of such information may not always appreciate its practical significance

for employee selection (Mattern, Kobrin, Patterson, Shaw, \& Camara, 2009). The relative persuasiveness of statistical vs. narrative evidence in other contexts has also been mixed (Allen \& Preiss, 1997; Hoeken \& Hustinx, 2009). In Study 2, we extend findings from study 1 by comparing the effectiveness of narrative evidence with statistical evidence. Specifically, we examine if presenting managers with the predictive validity of the structured interview is more effective than narrative evidence with respect to attitude change. Given the inconclusive findings from the literature, no a priori hypothesis is made. 
Although we previously theorized that stories could reduce resistance via increased transportation, this mediation pathway was not explicitly tested in Study 1. In Study 2, we empirically test the full theoretical model by examining narrative transportation in a multi-step mediation model (Figure 1). We expect that the persuasive effects of stories on attitude change with respect to structured interview use will be mediated by narrative transportation and resistance.

Hypothesis 6a. Participants reading a story will experience greater narrative transportation compared to reading advice.

Hypothesis $6 \mathrm{~b}$. Narrative transportation will be negatively related to counterarguing such that participants who experience greater transportation to the message content will engage in less counterarguing.

Hypothesis 7. Narrative transportation and counterarguing will mediate the relationship between message content and attitude change toward structured interview usage such that the indirect effect will be carried through narrative transportation and counterarguing sequentially.

Finally, in Study 2, we set out to extend the findings of Study 1 in a sample of managers using a pretest-posttest design. Specifically, participants indicated their attitudes toward the structured interview prior to and after receiving the message content manipulation. By doing so, we were able to examine the magnitude of attitude change based on whether the participant read about the effectiveness of structured interviews in a narrative format or advice format. Testing the hypotheses with managers allowed us to generalize our findings to a more relevant sample.

\section{Study 2: Methods}

\section{Sample}


The sample size was determined based on the results of an a priori power analysis conducted for a repeated measure (pretest vs. posttest) two-group (advice vs. story) design. A study with $90 \%$ power to detect a small effect size required 171 participants. To account for unusable data (missing data, inattentive responses), we gathered data from 200 Prolific workers. Prolific $^{3}$ is an online crowdsourcing platform used for recruiting a diverse sample of participants in social science research. Unlike other popular platforms (e.g., Amazon Mechanical Turk), Prolific is dedicated for research participation. In a review of various crowdsourcing research platforms, Peer, Brandimarte, Samat, and Acquisti (2017) found that participants on Prolific were more diverse than MTurk, provided higher quality data than traditional participant pools (e.g., college students), and generally more naïve to common experimental paradigms. One specific advantage of Prolific is the ability to pre-screen participants based on a wide range of characteristics (e.g., occupation, number of subordinates, supervisory experience).

For this study, eligible participants must 1) have leadership/position of power/supervisory duties, 2) have management experience, 3) have experience in making hiring decisions, and 4) currently employed ${ }^{4}$. Three participants were removed from the dataset for failing to answer the attention check question (e.g., "Please respond to this statement with the strongly disagree option"). The final sample consisted of 197 participants (Mean age $=40 ; 50 \%$ Male; $90 \%$ Caucasian). Majority of the participants were from the United Kingdom (58\%) and the United States of America (29\%).

\footnotetext{
${ }^{3}$ www.prolific.ac

${ }^{4}$ The inclusion criteria reduced the eligible population on Prolific down to 1723 participants (roughly $3 \%$ of the total Prolific participant pool). Eligible participants received emails notifying them of the study.
} 


\section{Procedure}

We used a 2 (message content: advice vs. story) x 2 (statistical evidence: statistical evidence vs. no evidence) between-subjects pretest-posttest experimental design. First, participants were asked to read information about structured job interviews and traditional interviews and answered questions regarding their attitudes towards structured job interview at their current place of work as well as their interviewing practices. Next, participants were randomly assigned to one of the four different conditions; they read either the advice or story version of a presentation, with or without statistical information about structured job interviews. They completed measures of narrative transportation and counterarguing toward the message content. Finally, participants reported their post-treatment attitudes toward structured job interviews.

\section{Script Development}

In Study 2, we prompted the participants to imagine that they are at an HR conference and provided them with transcripts of the presentation on structured job interviews for interviewing job applicants. We gave the participants a description of structured interviews and told them that they would be asked some questions about the presentation afterward. We generated key messages for the presentation and expanded upon the message for either the story or advice condition. The scripts are similar to those used in Study 1. Because it is plausible that conference presentations may include research evidence, we also included statistical information as an IV. See Appendix $C^{5}$ for the key messages and the presentation content.

\footnotetext{
${ }^{5}$ The story and advice scripts each scored an 9 on the Flesch-Kincaid Grade Level readability scale (calculated with www.grammarly.com), which indicates that both scripts were written at no higher than a high school reading level. Stories also had similar word count (168 vs. 190); word
} 


\section{Measures}

Attitudes toward structured interview usage. A four-item scale was developed to measure people's intentions to utilize and recommend a structured interview. Participants were asked the following questions before (pretest) and after (posttest) reading the message content. The items were 1) "how likely are you to endorse the structured job interview for making hiring decisions at your organization?", 2) "how likely are you to recommend the structured job interview to leaders of your organization?", 3) "how likely are you to suggest the structured job interview to your colleagues?", and 4) "how likely are you to personally adopt the structured job interview procedure for making hiring-related decisions?". The scale had good reliability (Cronbach's $\alpha=0.97$ ).

Narrative Transportation. We used nine items from Green and Brock's (2000) Narrative Transportation Scale. Given that the original scale was developed to measure transportation while watching a video, we modified some of the items to suit the nature of the stimulus in this study better. An example item is "When I was reading the script, I could easily picture the events in it taking place." The scale had acceptable reliability (Cronbach's $\alpha=0.76$ )

Counterarguing. We used the same three-item self-report measure from Study 1 . The scale had acceptable reliability (Cronbach's $\alpha=0.81$ ).

Hiring Experience. We used three items of hiring experience adapted from Nolan et al., 2016. We asked participants to consider their current job responsibilities and indicate how often

per sentence (16 vs. 16); and number of 6-letter or more words (31\% vs. $29 \%$ ). LIWC also revealed similar proportion of positive $(2.28 \%$ vs $3.16 \%)$ and negative $(1.19 \%$ vs. $1.05 \%)$ emotion words between two scripts. 
they 1) review/evaluated applicant materials; 2) conduct employment interviews; and 3) make hiring recommendations/decisions. Response options for hiring experience were $1=$ Never; $2=$ Once or twice; $3=$ Once or twice each year; $4=$ Once or twice each month; $5=$ once or twice each week; 6 = almost every day. We formed an overall composite measure of hiring experience by aggregating across the three items. The scale had good reliability (Cronbach's $\alpha=0.88$ ).

At the start of the study, we also asked participants to indicate, using a single item, the degree to which their current interviewing procedure is structured ("Think about how you typically have interviewed potential job candidates. To what degree have those job interviews been structured?”). Participants responded from $1=$ not at all structured to $5=$ completely structured.

\section{Study 2: Results and Discussion}

Means, standard deviations, and correlations are reported in Table 5. The participants' report of current interviewing practice was negatively correlated with their counterarguing. Specifically, participants who reported that their company uses more structured interviews engaged in less counterarguing against the message that structured interviews are effective. Relatedly, those participants also reported higher transportation with the message overall. Importantly, there was a strong correlation between the reported interviewing practice of their company and participant's personal attitude toward structured interviewing at the pre-test phase. The findings suggest that people's attitudes toward structured interview may be heavily informed by the organizational practices. Given the observed significant correlation between the statistical information manipulation and hiring experience, we examined the robustness of the results by controlling for hiring experience. 
Analysis of variance results revealed a significant effect of message content (story vs. advice) on the participants' counterarguing, $F(1,193)=14.47, p<.001$, and transportation $F(1,193)=7.26, p=.01$. Replicating results from Study 1, participants in the story condition engaged in less counterarguing $(M=2.12, S D=.83)$ than those in the advice condition $(M=$ 2.63, $S D=1.07$ ). Also, as predicted, participants in the story condition also reported higher transportation $(M=3.53, S D=.53)$ than those in the advice condition $(M=3.32, S D=.57)$. Therefore, Hypothesis 7 was supported. We did not find a significant effect of statistical evidence on counterarguing or narrative transportation. All other interaction terms did not reach statistical significance for either of the dependent variables.

Next, we conducted a repeated-measures ANOVA to examine the effects of message content and statistical evidence on attitude change. Pretest and posttest attitudes toward the structured interview usage were treated as a within-subject variable. First, there was a significant main effect of the persuasive intervention on people's attitudes toward the structured interview, $F(1,193)=64.48, p<.001$. People reported significantly higher structured interview use intentions after $(M=3.75, S D=1.11)$ than before $(M=3.25, S D=1.27)$ reading the presentation script. Most importantly, we observed a significant interaction between the within-subject variable (pretest vs. posttest) and script content (story vs. advice) on managers' reported attitudes toward the structured interview, $F(1,193)=5.35, p=.022$, Cohen's $d_{p p c}{ }^{6}=0.22$. In other words, the pretest-posttest change in attitude toward the structured interview was greater when the

\footnotetext{
6 The Cohen's $d_{p p c}$ provides a standard estimate of the between-subject treatment (script content) effect size in a pretest-posttest control design (Morris, 2008).
} 
participant read a story vs. advice. Therefore, we found support for Hypothesis $2^{7}$. We did not, however, find a significant interaction between the persuasion treatment and statistical evidence. Table 6 contains the means of pre- and post-treatment attitudes toward the structured interview usage for each condition.

\section{Mediation Analysis}

We tested the serial indirect effect of the impact of the message content (narrative/advice) on attitude change via narrative transportation and reported counterarguing (Figure 1).

Bootstrapped estimated $95 \%$ confidence intervals for the indirect effects were estimated using the lavaan package in $R$. As seen in Table 4 , the $95 \%$ confidence interval of the serial indirect effect of message content $\rightarrow$ narrative transportation $\rightarrow$ counterarguing $\rightarrow$ attitude change did not include zero, which suggest a significant indirect effect. In other words, managers in the narrative condition reported greater narrative transportation, and as a result, they were less likely to counterargue against the use of structured interviews. Moreover, the reduction in counterarguing increased the magnitude of pretest-posttest change in manager's intentions to use the structured job interview. Therefore, Hypothesis 6 and 7 was supported. In Study 1, we demonstrated that when participants read a narrative regarding structured interviews, they engage in less counterarguing, which results in more favorable attitudes toward structured interviews. In Study 2, we expanded upon the mediation analysis of Study 1 to include transportation to message and attitude change regarding utilization of structured interview. Additionally, we

\footnotetext{
${ }^{7}$ Although a random assignment is used. We observed a small, but significant difference in hiring experience between the two levels of the statistical evidence condition, $t(189)=1.98$, $p_{\text {uncorrected }}=.049$. As a robustness check, we tested the main hypothesis with a Repeated ANCOVA with hiring experience held as a between-groups covariate. The primary interaction term (Content $\mathrm{x}$ treatment) was nearly identical, $F(1,192)=5.29, p=.022$.
} 
focused on a sample of managers who make hiring decisions for their organizations. In sum, Study 2 showed that when managers are presented with the benefits of structured interviews in a narrative format, they are more engaged with the persuasive message and are less likely to counterargue. As a result, they are more likely to change their attitudes toward utilization of structured interviews at their organizations.

\section{General Discussion}

Whether presenting to a boardroom of CEOs or speaking to the public about research findings, researchers need to carefully craft how they communicate their message in order to have the biggest impact (Aguinis et al., 2010). Effective and persuasive communication is particularly important when bridging the scientist-practitioner gap and trying to overcome existing biases or resistance against evidence-based HR practices (e.g., structured job interviews). In this research, we found that stories - in contrast with advice - was more effective in communicating to the decision makers on the efficacy of structured job interviews and increased their likelihood to utilize them in an employment setting.

In the first study, adult participants who read a story about the effectiveness of structured interviews reported lower counterarguing, which is the generation of direct rebuttals against the utility of structured interviews. We also found that the engagement of counterarguing had a causal effect on subsequent attitude. Participants who reported less counterarguing had more favorable attitudes toward the structured interview. We conducted a conceptual replication and extension in the second study by examining the persuasive effects of stories on a sample of HR professionals. Moreover, we also examined the psychological mechanisms underlying the narrative persuasion process. Consistent with transportation theory, the reduction in 
counterarguing from reading a story was mediated by narrative transportation. Taken together, these findings illustrated the value of using stories as a method for researchers and communicators to overcome people's resistance toward evidence-based hiring practices, especially ones that are traditionally resisted by hiring professionals.

Although we did not find an effect of character background on the persuasiveness of the story in the first study, others have found that stories are more persuasive when the audience can relate to the characters in the story (Moyer-Gusé et al., 2011). One explanation for the lack of significant findings is that our stimulus material was too short to develop a rich background. In many full-length stories in books and movies, a significant portion of the narrative focuses on character development. Indeed, it is likely that full-length books will be more persuasive than a short article in a magazine. However, in real-world communication, this is not practical. Although the length of the stimulus limited the amount of background information provided for the story characters, the amount of information more realistically mirrors the communication of narratives in the real world and provides a more conservative test of the effects of narratives.

In the second study, the presence of statistical information did not enhance the persuasiveness of the story and advice scripts. Although past research has shown that the combination of statistical and narrative evidence is the most powerful, this was not the case in this study. One possible explanation is the type of statistical information used in this study. Participants were presented with a traditional effect size index (Pearson's correlation). Recent research, however, has shown that traditional effect size statistics may not adequately communicate the value of evidence-based hiring practices (Brooks, Dalal, \& Nolan, 2014; Zhang, 2018b). Therefore, it is possible that alternative displays of validity evidence (e.g., 
expectancy chart or binomial effect size display) may further enhance the persuasiveness of stories.

\section{Limitations and Future Directions}

First, all experiments are potentially limited by their external validity and generalizability beyond the lab setting (Anderson \& Bushman, 1997; Ilgen, 1985). Therefore, it is possible - and expected - that the persuasive effects of stories may differ depending on the audience (e.g., an executive who is responsible for the hiring practices of their company vs. a job applicant with little interview experience). Moreover, not all stories are equally persuasive, even multi-milliondollar advertisements with stunning visuals and carefully scripted storylines can backfire.

Nevertheless, concerns about external validity and generalizability do not discount the theorized effects found in our experiments (Highhouse, 2009). Second, we recognize potential confounding variables that could have affected our results, such as the tone of voice and formality of speech. Our aim, however, was to demonstrate that a story, given its innate properties, can improve the persuasiveness of a message beyond factual and statistical advice. Indeed, more basic research is needed to address the individual elements of storytelling that could enhance its effectiveness. Third, given the design of Study 2, some of the pretest-posttest difference may be attributed to demand effects. However, because a between-subject manipulation was used, we can be confident that the difference in the attitude change must be, at least in part, due to the content of the message, above and beyond demand characteristics.

Future Research. Future research on narrative persuasion should examine factors that may enhance narrative transportation or further reduce counterarguing. First, research could examine the role of vividness on narrative transportation (Sherer \& Rogers, 1984). Vivid stories 
draw the audience into the fictitious world where facts presented in the narrative world are more readily accepted. Some researchers have started examining the role of story delivery format (e.g., multimedia) on vividness and transportation (Lien \& Chen, 2013). Given the varieties of ways in which information can be delivered with modern technology, it is important to identify the best combination of medium and presentation style to maximize the persuasiveness of stories.

Relatedly, as a reviewer suggested, the technicality of the language may also affect the persuasive efficacy of stories. Indeed, more basic and applied research is needed to better understand how linguistic presentation affects attitude change. Second, future research should consider the optimal ways to combine narrative and statistical evidence. A growing body of data visualization research has provided researchers with a considerable number of possible tools, but more empirical research is needed to examine how data and stories may be integrated with the organizational sciences. Third, not all receivers are equally receptive to being persuaded. Individual difference factors such as open-minded thinking, need for cognition, or transportability may serve moderators of persuasive efficacy (Kaufman, Stasson, \& Hart, 1999; Mazzocco, Green, Sasota, \& Jones, 2010; Stanovich \& West, 1997). Finally, future research should expand its methodological repertoire to include qualitative approaches, which may complement existing research on why evidence-based hiring practices are underutilized.

\section{Implications for Practice}

Stories can promote other managerial and organizational practices where there exists a science-practice gap: such as work-family interventions, employee safety programs, or customer service focus. Indeed, several academics have recommended using stories to bridge the gap between science and practice (Kuncel, 2008; Rynes et al., 2018). Academics may also use stories 
in their interactions with organizational stakeholders to foster meaningful collaborations (Zhang, 2018a). Therefore, we suggest scientists and practitioners include a story to accompany their advice when communicating the value of evidence-based practices in workshops, popular media (e.g., TED Talks), and mainstream publications (e.g., NYTimes, Harvard Business Review).

Recommendations for persuasive storytelling. In order to enhance the persuasiveness of the story, the storyteller should incorporate relatable characters, which may be achieved by using a personal anecdote, or a well-recognized character. In doing so, the storyteller grounds the audience in a believable narrative world. The storyteller should pay attention to the persuasive content of the story, which can be embedded into a story using explicit or implicit statements. In explicit statements, the character describes a series of events and facts that lead to an explicit declaration of the final resolution. Implicit statements, on the other hand, provide grounds for inference about the story's message through a series of events experienced by the storyteller. For example, the characters in our story do not explicitly advocate the use of structured interview, but its value is implied in the resolution because of the positive outcome of its adoption (the consultant was contracted to work for the company due to the structured interview). We recognize that stories, due to their anecdotal nature, contradict the general spirit of evidencebased decisions. Therefore, we suggest that stories should be accompanied by empirical evidence. It is important to note that we do not advocate the disingenuous use of stories in the absence of evidence for the sole purpose of persuasion.

\section{Conclusion}

Rynes (2009) commented that "one of the most widely documented and persistent of these gaps involves practitioner preferences for using intuitive methods of selection, particularly 
unstandardized employment interviews" (p. 412). Bridging the gap between science and practice involves communicating research findings in a persuasive manner. Our research suggests that storytelling has practical value for persuasion and science communication. We showed that stories could reduce resistance toward story-consistent information by transporting the reader to the scene of the story. In our study, by reading a story about the success of a structured interview, readers reported more favorable attitudes toward its adoption. Historically, storytelling has been a successful tool for attitude change in other disciplines. Our study provides evidence for its efficacy in changing managers' attitudes towards pre-employment structured interviews. 


\section{References}

Aguinis, H., Werner, S., Lanza Abbott, J., Angert, C., Park, J. H., \& Kohlhausen, D. (2010). Customer-centric science: Reporting significant research results with rigor, relevance, and practical impact in mind. Organizational Research Methods, 13(3), 515-539.

Allen, M., \& Preiss, R. W. (1997). Comparing the persuasiveness of narrative and statistical evidence using meta-analysis. Communication Research Reports, 14(2), 125-131.

Anderson, C. A., \& Bushman, B. J. (1997). External validity of "trivial" experiments: The case of laboratory aggression. Review of General Psychology, 1(1), 19-41.

Bartunek, J. M. (2007). Academic-practitioner collaboration need not require joint or relevant research: Toward a relational scholarship of integration. Academy of Management Journal, 50(6), 1323-1333.

Best, J. (2001). Damned Lies and Statistics: Untangling Numbers from the Media, Politicians, and Activists. University of California Press.

Bilandzic, H., \& Busselle, R. (2013). Narrative persuasion. The Sage Handbook of Persuasion: Developments in Theory and Practice, 200-219.

Braddock, K., \& Dillard, J. P. (2016). Meta-analytic evidence for the persuasive effect of narratives on beliefs, attitudes, intentions, and behaviors. Communication Monographs, 83(4), 446-467.

Broockman, D., \& Kalla, J. (2016). Durably reducing transphobia: A field experiment on doorto-door canvassing. Science, 352(6282), 220-224. 
Brooks, M. E., Dalal, D. K., \& Nolan, K. P. (2014). Are common language effect sizes easier to understand than traditional effect sizes? The Journal of Applied Psychology, 99(2), 33240. https://doi.org/10.1037/a0034745

Caprar, D. V., Do, B., Rynes, S. L., \& Bartunek, J. M. (2016). It's Personal: An Exploration of Students' (Non)Acceptance of Management Research. Academy of Management Learning \& Education, 15(2), 207-231. https://doi.org/10.5465/amle.2014.0193

Chen, Y.-C., Tsai, W.-C., \& Hu, C. (2008). The influences of interviewer-related and situational factors on interviewer reactions to high structured job interviews. International Journal of Human Resource Management, 19(6), 1056-1071. https://doi.org/10.1080/09585190802051345

Cheung, J. H., Burns, D. K., Sinclair, R. R., \& Sliter, M. (2016). Amazon Mechanical Turk in Organizational Psychology: An Evaluation and Practical Recommendations. Journal of Business and Psychology, 1-15. https://doi.org/10.1007/s10869-016-9458-5

Dahlstrom, M. F. (2014). Using narratives and storytelling to communicate science with nonexpert audiences. Proceedings of the National Academy of Sciences, 111(Supplement_4), 13614-13620. https://doi.org/10.1073/pnas.1320645111

Dana, J., Dawes, R., \& Peterson, N. (2013). Belief in the unstructured interview: The persistence of an illusion. Judgment and Decision Making, 8(5), 512-520.

de Graaf, A., Hoeken, H., Sanders, J., \& Beentjes, J. W. J. (2012). Identification as a Mechanism of Narrative Persuasion. Communication Research, 39(6), 802-823. https://doi.org/10.1177/0093650211408594 
Dunlop, P. D., \& Lee, K. (2004). Workplace deviance, organizational citizenship behavior, and business unit performance: The bad apples do spoil the whole barrel. Journal of Organizational Behavior: The International Journal of Industrial, Occupational and Organizational Psychology and Behavior, 25(1), 67-80.

Fernandez, S., \& Pougnet, S. (2018). Is there structure in the selection interview? Evidence from hotels in Switzerland. Journal of Human Resources in Hospitality \& Tourism, 17(1), 8097. https://doi.org/10.1080/15332845.2017.1328262

Green, M. C., \& Brock, T. C. (2000). The role of transportation in the persuasiveness of public narratives. Journal of Personality and Social Psychology, 79(5), 701.

Green, M. C., Brock, T. C., \& Kaufman, G. F. (2004). Understanding media enjoyment: The role of transportation into narrative worlds. Communication Theory, 14(4), 311-327.

Hayton, J. C., Allen, D. G., \& Scarpello, V. (2004). Factor retention decisions in exploratory factor analysis: A tutorial on parallel analysis. Organizational Research Methods, 7(2), 191-205.

Highhouse, S. (2008). Stubborn reliance on intuition and subjectivity in employee selection. Industrial and Organizational Psychology, 1(3), 333-342. https://doi.org/10.1111/j.17549434.2008.00058.x

Highhouse, S. (2009). Designing Experiments That Generalize. Organizational Research Methods, 12(3), 554-566. https://doi.org/10.1177/1094428107300396

Highhouse, S., Brooks, M. E., Nesnidol, S., \& Sim, S. (2017). Is a .51 validity coefficient good? Value sensitivity for interview validity. International Journal of Selection and Assessment, 25(4), 383-389. https://doi.org/10.1111/ijsa.12192 
Highhouse, S., Nye, C. D., \& Zhang, D. C. (2018). Dark Motives and Elective Use of Brainteaser Interview Questions. Applied Psychology. https://doi.org/10.1111/apps.12163

Highhouse, S., \& Zhang, D. (2015). The New Fruit Fly for Applied Psychological Research. Industrial and Organizational Psychology, 8(02), 179-183. https://doi.org/10.1017/iop.2015.22

Hinyard, L. J., \& Kreuter, M. W. (2006). Using narrative communication as a tool for health behavior change: A conceptual, theoretical, and empirical overview. Health Education \& Behavior.

Hoeken, H., \& Hustinx, L. (2009). When is statistical evidence superior to anecdotal evidence in supporting probability claims? The role of argument type. Human Communication Research, 35(4), 491-510.

Huffcutt, A. I., \& Arthur, W. (1994). Hunter and Hunter (1984) revisited: Interview validity for entry-level jobs. Journal of Applied Psychology, 79(2).

Huffcutt, A. I., \& Roth, P. L. (1998). Racial group differences in employment interview evaluations. Journal of Applied Psychology, 83(2), 179-189. https://doi.org/10.1037/0021-9010.83.2.179

Humphreys, L. G., \& Montanelli Jr, R. G. (1975). An investigation of the parallel analysis criterion for determining the number of common factors. Multivariate Behavioral Research, 10(2), 193-205.

Ilgen, D. (1985). Laboratory research: A question of when, not if.

Johnson, M. K., Hashtroudi, S., \& Lindsay, D. S. (1993). Source monitoring. Psychological Bulletin, 114(1), 3. 
Kaiser, H. F. (1960). The Application of Electronic Computers to Factor Analysis. Educational and Psychological Measurement, 20(1), 141-151. https://doi.org/10.1177/001316446002000116

Kaufman, D. Q., Stasson, M. F., \& Hart, J. W. (1999). Are the tabloids always wrong or is that just what we think? Need for cognition and perceptions of articles in print media. Journal of Applied Social Psychology, 29(9), 1984-2000.

Kausel, E. E., Culbertson, S. S., \& Madrid, H. P. (2016). Overconfidence in personnel selection: When and why unstructured interview information can hurt hiring decisions. Organizational Behavior and Human Decision Processes, 137, 27-44. https://doi.org/10.1016/j.obhdp.2016.07.005

Kirsch, I. S., Jungeblut, A., Jenkins, L., \& Kolstad, A. (2002). Adult Literacy in America: A First Look at the Findings of the National Adult Literacy Survey. Retrieved September 21, 2016, from https://nces.ed.gov/pubsearch/pubsinfo.asp?pubid=93275

Knowles, E. S., \& Linn, J. A. (2004). Resistance and persuasion. Psychology Press.

Kopfman, J. E., Smith, S. W., Ah Yun, J. K., \& Hodges, A. (1998). Affective and cognitive reactions to narrative versus statistical evidence organ donation messages.

Kuncel, N. R. (2008). Some New (and Old) Suggestions for Improving Personnel Selection. Industrial and Organizational Psychology, 1(03), 343-346. https://doi.org/10.1111/j.1754-9434.2008.00059.x

Kunda, Z. (1990). The case for motivated reasoning. Psychological Bulletin, 108(3), 480. 
Levashina, J., Hartwell, C. J., Morgeson, F. P., \& Campion, M. A. (2014). The structured employment interview: Narrative and quantitative review of the research literature. Personnel Psychology, 67(1), 241-293.

Lewis, M. (2004). Moneyball: The art of winning an unfair game. WW Norton \& Company.

Lien, N.-H., \& Chen, Y.-L. (2013). Narrative ads: The effect of argument strength and story format. Journal of Business Research, 66(4), 516-522. https://doi.org/10.1016/j.jbusres.2011.12.016

Lievens, F., \& De Paepe, A. (2004). An empirical investigation of interviewer-related factors that discourage the use of high structure interviews. Journal of Organizational Behavior, 25(1), 29-46.

Lubbe, D., \& Nitsche, A. (2019). Reducing assimilation and contrast effects on selection interview ratings using behaviorally anchored rating scales. International Journal of Selection and Assessment, O(0). https://doi.org/10.1111/ijsa.12230

Macan, T. H., \& Highhouse, S. (1994). Communicating the utility of human resource activities: A survey of I/O and HR professionals. Journal of Business and Psychology, 8(4), 425436.

Mattern, K., Kobrin, J., Patterson, B., Shaw, E., \& Camara, W. (2009). Validity is in the eye of the beholder: Conveying SAT research findings to the general public. In R. W. Lissitz (Ed.), The concept of validity: Revisions, new directions, and applications (pp. 213-40). Charlotte, NC: Information Age Publishing. 
Mazzocco, P. J., Green, M. C., Sasota, J. A., \& Jones, N. W. (2010). This story is not for everyone: Transportability and narrative persuasion. Social Psychological and Personality Science, 1(4), 361-368.

Moore, D. A. (2017). How to Improve the Accuracy and Reduce the Cost of Personnel Selection. California Management Review, 60(1), 8-17. https://doi.org/10.1177/0008125617725288

Morris, S. B. (2008). Estimating Effect Sizes From Pretest-Posttest-Control Group Designs. Organizational Research Methods, 11(2), 364-386. https://doi.org/10.1177/1094428106291059

Moyer-Gusé, E. (2008). Toward a theory of entertainment persuasion: Explaining the persuasive effects of entertainment-education messages. Communication Theory, 18(3), 407-425.

Moyer-Gusé, E., Chung, A. H., \& Jain, P. (2011). Identification With Characters and Discussion of Taboo Topics After Exposure to an Entertainment Narrative About Sexual Health. Journal of Communication, 61(3), 387-406. https://doi.org/10.1111/j.14602466.2011.01551.x

Moyer-Gusé, E., \& Nabi, R. L. (2010). Explaining the persuasive effects of entertainmenteducation: An empirical comparison of three theories. Human Communication Research, $36,26-52$.

Nolan, K., Carter, N. T., \& Dalal, D. K. (2016). Threat of technological unemployment: Are hiring managers discounted for using standardized employee selection practices? 2(1).

Pearl, J., \& Mackenzie, D. (2018). The book of why: The new science of cause and effect. Basic Books. 
Peer, E., Brandimarte, L., Samat, S., \& Acquisti, A. (2017). Beyond the Turk: Alternative platforms for crowdsourcing behavioral research. Journal of Experimental Social Psychology, 70, 153-163.

Pennebaker, J. W., Francis, M. E., \& Booth, R. J. (2001). Linguistic inquiry and word count: LIWC 2001. Mahway: Lawrence Erlbaum Associates, 71(2001), 2001.

Petty, R. E., Tormala, Z. L., \& Rucker, D. D. (2004). Resisting persuasion by counterarguing: An attitude strength perspective. (J. T. Jost, M. R. Banaji, \& D. A. Prentice, Eds.). In (pp. 37-51). Washington, DC, US: American Psychological Association.

Podsakoff, P. P. M., MacKenzie, S. S. B., Lee, J. Y., \& Podsakoff, N. P. (2003). Common method biases in behavioral research: A critical review of the literature and recommended remedies. Journal of Applied \dots, 88(5), 879-903. https://doi.org/10.1037/0021-9010.88.5.879

Ratcliff, R., \& Smith, P. (2004). A comparison of sequential sampling models for two-choice reaction time. Psychological Review, 111(2), 333-367. https://doi.org/10.1037/0033295X.111.2.333

Ricketts, M., Shanteau, J., McSpadden, B., \& Fernandez-Medina, K. M. (2010). Using stories to battle unintentional injuries: Narratives in safety and health communication. Social Science \& Medicine, 70(9), 1441-1449. https://doi.org/10.1016/j.socscimed.2009.12.036

Roulin, N., \& Bangerter, A. (2012). Understanding the Academic-Practitioner Gap for Structured Interviews:'Behavioral'interviews diffuse, 'structured'interviews do not. International Journal of Selection and Assessment, 20(2), 149-158. 
Ryan, A. M., \& Ployhart, R. E. (2014). A Century of Selection. Annual Review of Psychology, 65(1), 693-717. https://doi.org/10.1146/annurev-psych-010213-115134

Rynes, S. (2009). The research-practice gap in industrial-organizational psychology and related fields: Challenges and potential solutions.

Rynes, S. L., \& Bartunek, J. M. (2017). Evidence-Based Management: Foundations, Development, Controversies and Future. Annual Review of Organizational Psychology and Organizational Behavior, 4(1), 235-261. https://doi.org/10.1146/annurev-orgpsych032516-113306

Rynes, S. L., Colbert, A. E., \& O’Boyle, E. H. (2018). When the "Best Available Evidence" Doesn't Win: How Doubts About Science and Scientists Threaten the Future of Evidence-Based Management. JOURNAL OF MANAGEMENT, 44, 995 -3010.

Schank, R. C., \& Berman, T. R. (2002). The pervasive role of stories in knowledge and action. NJ: Lawrence Erlbaum.: Mahwah.

Sherer, M., \& Rogers, R. W. (1984). The role of vivid information in fear appeals and attitude change. Journal of Research in Personality, 18(3), 321-334.

Slater, M. D., \& Rouner, D. (2002a). Entertainment—education and elaboration likelihood: Understanding the processing of narrative persuasion. Communication Theory, 12(2), $173-191$.

Slater, M. D., \& Rouner, D. (2002b). Entertainment-education and elaboration likelihood: Understanding the processing of narrative persuasion. Communication Theory, 12(2), $173-191$. 
Stanovich, K. E., \& West, R. F. (1997). Reasoning independently of prior belief and individual differences in actively open-minded thinking. Journal of Educational Psychology, 89(2), 342.

Tausczik, Y. R., \& Pennebaker, J. W. (2010). The psychological meaning of words: LIWC and computerized text analysis methods. Journal of Language and Social Psychology, 29(1), $24-54$.

Tsai, W.-C., HsinHung Chen, F., Chen, H.-Y., \& Tseng, K.-Y. (2016). When Will Interviewers Be Willing to Use High-structured Job Interviews? The role of personality: Highstructured Interviews. International Journal of Selection and Assessment, 24(1), 92-105. https://doi.org/10.1111/ijsa.12133

Tversky, A., \& Koehler, D. (1994). Support theory: A nonextensional representation of subjective probability. Psychological Review, 101(4), 547-567.

Van der Zee, K. I., Bakker, A. B., \& Bakker, P. (2002). Why are structured interviews so rarely used in personnel selection? Journal of Applied Psychology, 87(1), 176.

Williamson, L., Campion, J., \& Malos, S. (1997). Employment interview on trial: Linking interview structure with litigation outcomes. Journal of Applied.

Wojcieszak, M., \& Kim, N. (2016). How to improve attitudes toward disliked groups: The effects of narrative versus numerical evidence on political persuasion. Communication Research, 43(6), 785-809.

Zhang, D. C. (2018a). Art of the Sale: Recommendations for Sharing Research With Mainstream Media and Senior Leaders. Industrial and Organizational Psychology, 11(4), 589-593. https://doi.org/10.1017/iop.2018.119 
Zhang, D. C. (2018b). Utility of Alternative Effect Size Statistics and the Development of a Web-Based Calculator: Shiny-AESC. Frontiers in Psychology, 9. https://doi.org/10.3389/fpsyg.2018.01221

Zhang, D. C., Highhouse, S., Brooks, M. E., \& Zhang, Y. (2018). Communicating the validity of structured job interviews with graphical visual aids. International Journal of Selection and Assessment, 26(2-4), 93-108. https://doi.org/10.1111/ijsa.12220

Zhu, X. S., Barnes-Farrell, J. L., \& Dalal, D. K. (2015). Stop Apologizing for Your Samples, Start Embracing Them. Industrial and Organizational Psychology, 8(02), 228-232. 


\section{Table 1}

Factor Loadings of The Self-Report Items for Counterarguing And Attitudes Toward Structured Interviews

\begin{tabular}{|c|c|c|}
\hline \multirow[b]{2}{*}{ Item } & \multicolumn{2}{|c|}{ Factor } \\
\hline & 1 & 2 \\
\hline Counterargue 1 & & 0.600 \\
\hline Counterargue 2 & & 0.967 \\
\hline Counterargue 3 & & 0.598 \\
\hline Structured interview attitudes 1 & 0.858 & \\
\hline Structured interview attitudes 2 & 0.787 & \\
\hline Structured interview attitudes 3 & -0.689 & \\
\hline Structured interview attitudes 4 & -0.655 & \\
\hline
\end{tabular}

Note. Minimum residual extraction method was used in combination with an Oblimin rotation. Factors loading less than 0.30 are omitted 


\section{Table 2}

Means, Standard Deviations, and Intercorrelation of Study 1 Variables

\begin{tabular}{|c|c|c|c|c|c|c|c|c|c|c|}
\hline Variable & $\mathrm{M}$ & SD & 1 & 2 & 3 & 4 & 5 & 6 & 7 & 8 \\
\hline 1. Counterarguing & 2.94 & 0.92 & & & & & & & & \\
\hline 2. Tentativeness & 7.25 & 4.91 & -.12 & & & & & & & \\
\hline 3. Attitudes toward Structured Interviews & 3.61 & 0.93 & $-.50 * *$ & $.13^{*}$ & & & & & & \\
\hline 4. Interview Experience & 2.42 & 1.28 & $.15^{*}$ & -.04 & -.01 & & & & & \\
\hline 5. Factor - Background & 0.50 & 0.50 & .03 & -.03 & -.08 & .02 & & & & \\
\hline 6. Factor - Content & 0.45 & 0.50 & $-.19 * *$ & $.13^{*}$ & .08 & .00 & -.03 & & & \\
\hline 7. Factor - Argue Order & 0.53 & 0.50 & $-.17 * *$ & .02 & $.35^{* *}$ & .03 & .00 & .11 & & \\
\hline 8. Age & 35.73 & 10.87 & .01 & .12 & $.18 * *$ & $.25 * *$ & -.00 & .06 & -.03 & \\
\hline 9. Sex & 0.50 & 0.50 & -.09 & -.01 & $.14^{*}$ & -.04 & .05 & .07 & .07 & .12 \\
\hline
\end{tabular}

Note. ${ }^{*} .=\mathrm{p}<0.05, * * .=\mathrm{p}<0.01 ;$ Sex is coded as $0=$ Women, $1=$ Men. Interview Experience is coded as $1=0$ job interviews conducted; $2=$ one to five; $3=$ six to ten; $4=$ eleven to twenty; $5=$ more than twenty. Background Factor is coded as $0=$ Impoverished; $1=$ Rich. Content Factor is coded as $0=$ Advice; $1=$ Story. Factor Argue Order is coded as $0=$ After; $1=$ Before. 
Table 3

Means and Standard Deviations of Dependent Variables Across Cells in Study 1

\begin{tabular}{lcccc}
\hline & \multicolumn{2}{c}{ Advice } & \multicolumn{2}{c}{ Narrative } \\
\cline { 2 - 5 } Argue Order & $M$ & $S D$ & $M$ & $S D$ \\
& 3.23 & 0.871 & 2.91 & 0.980 \\
Argue First & 2.96 & 0.884 & 2.63 & 0.886 \\
Argue Last & Attitudes toward Structured Interviews & \\
\hline & & & & \\
Argue First & 3.19 & 0.920 & 3.38 & 0.886 \\
Argue Last & 3.92 & 0.887 & 3.92 & 0.789 \\
\hline
\end{tabular}




\section{Table 4}

Estimates of Indirect Effects of Mediational Analyses in Studies 1 and 2

\begin{tabular}{lcc}
\hline Paths & $\begin{array}{c}\text { Unstandardized } \\
\text { Indirect Effect }\end{array}$ & $\begin{array}{c}\text { 95\% CI for } \\
\text { Unstandardized } \\
\text { Indirect Effect }\end{array}$ \\
\hline $\begin{array}{l}\text { Message Content } \rightarrow \\
\text { 1. Counterarguing } \rightarrow \text { Attitude Towards SI (Study 1) }\end{array}$ & $.09(.03)$ & {$[.03, .15]$} \\
2. Transportation $\rightarrow$ Counterarguing (Study 2) & $-.21(.08)$ & {$[-.39,-.06]$} \\
3. Transportation $\rightarrow$ Counterarguing $\rightarrow$ Attitude Change (Study 2) & $.05(.02)$ & {$[.01, .11]$} \\
\hline
\end{tabular}

Note. Message type included advice condition (coded as 0) and story condition (coded as 1); SI indicates structured interview; CI indicates confidence interval. 


\section{Table 5}

Means, Standard Deviations, and intercorrelations of Study 2's Variables

\begin{tabular}{|c|c|c|c|c|c|c|c|c|c|c|c|}
\hline Variable & M & $\mathrm{SD}$ & 1 & 2 & 3 & 4 & 5 & 6 & 7 & 8 & 9 \\
\hline 1. Hiring Experience & 3.09 & 1.00 & & & & & & & & & \\
\hline 2. Current Interview Practice & 3.15 & 1.33 & $.20 * *$ & & & & & & & & \\
\hline 3. Counterarguing & 2.38 & 1.00 & -.04 & $-.24 * *$ & & & & & & & \\
\hline 4. Transportation & 3.42 & 0.56 & $.22 * *$ & $.25 * *$ & $-.57 * *$ & & & & & & \\
\hline 5. Attitudes toward S.I. (Pretest) & 3.25 & 1.27 & .12 & $.60 * *$ & $-.38 * *$ & $.34 * *$ & & & & & \\
\hline 6. Attitudes toward S.I. (Posttest) & 3.75 & 1.11 & .11 & $.45^{* *}$ & $-.66 * *$ & $.56^{* *}$ & $.73 * *$ & & & & \\
\hline 7. Factor - Content & 0.49 & 0.50 & -.02 & .01 & $-.26 * *$ & $.19 * *$ & .09 & $.24 * *$ & & & \\
\hline 8. Factor - Statistical Evidence & 0.50 & 0.50 & $-.14 *$ & .00 & -.04 & .02 & -.04 & .00 & -.05 & & \\
\hline 9. Age & 39.74 & 10.35 & -.05 & -.04 & $-.16^{*}$ & .13 & .01 & .07 & -.09 & .05 & \\
\hline 10. Sex & 0.47 & 0.50 & -.09 & -.11 & .10 & -.13 & $-.15^{*}$ & $-.14^{*}$ & .02 & .09 & $-.17 *$ \\
\hline
\end{tabular}

Note. * indicates $\mathrm{p}<.05 . * *$ indicates $\mathrm{p}<.01$. Current Interview Practice is scored between 1 (Not at all structured) to 5 (Fully structured). Factor Content is coded as $0=$ Advice; $1=$ Story. Factor Statistical Evidence is coded as $0=$ No Statistics; $1=$ Evidence Present. Sex is coded as $0=$ Female, $1=$ Male. S.I. Indicates structured interviews. 
COMMUNICATING WITH STORYTELLING

Table 6

Means and Standard Deviations of Dependent Variables Across Cells in Study 2

Advice Narrative

Statistical Information $M$

$S D$

M

$S D$

Pre-Test Attitudes toward Structured Interviews

\begin{tabular}{lllll} 
Control & 3.24 & 1.29 & 3.35 & 1.28 \\
Present & 3.03 & 1.27 & 3.39 & 1.25 \\
\hline
\end{tabular}

Post-Test Attitudes toward Structured Interviews

\begin{tabular}{lllll} 
Control & 3.57 & 1.15 & 3.91 & 0.930 \\
Present & 3.42 & 1.27 & 4.13 & 0.916 \\
\hline
\end{tabular}




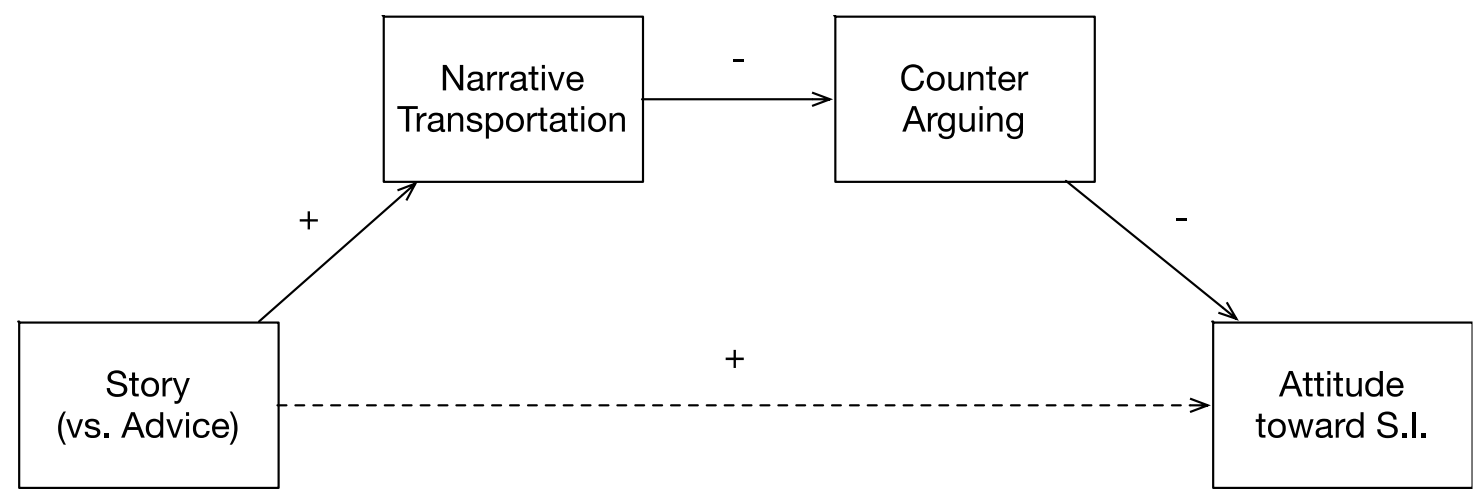

Figure 1. Theoretical Model of Narrative Persuasion and Structured Interview Attitudes. Note. S.I. indicates structured interviews. 
Appendix A

Story and Advice Scripts for Study 1

\section{Story Condition}

Q: Can you tell me about a recent client that you worked with?

A: Last summer, \{company name\} contacted our firm about helping them with assessments. They tend to hire student employees over the summer. For the past few years, they have experienced a lot of turnover because the students would work one summer and never return. They also observed theft and absenteeism on the job. I was put on the job with a team of three other psychologists. First, I sat down with the HR department and asked them to describe their current hiring process. He told me that most candidates are hired based on their resume and an informal interview. I met with a few managers over coffee and asked if they could describe their interview process, and no one could give me a good answer. They all just said they interviewed the applicants how they see fit. So, I decided to start fixing the problem there. I sat down with my team and asked the management about the most important traits they want in an applicant, like integrity, conscientiousness, and so on. Next, we developed interview questions that asked the applicant to describe their past behaviors that are relevant to those traits. This took a few weeks but eventually we had a list of questions. We also worked together to determine what makes a good answer, and how to rate the candidate's responses.

Q: How did it work out?

A: There was some opposition at first when we presented them with the structured interview system. Some of the hiring managers felt too constrained by our questions and they didn't like that. They preferred the traditional interviewing method where they weren't given a script and could ask whatever questions they thought best suited the situation. But we requested that they try it with a few lumberyards the first year and see how it goes. They ended up using this system for two of their lumberyards in the East Coast region. By the summer's end, they reported a significant drop-off in absenteeism and theft. They were so thrilled with our work that we are now contracted to implement structured interviews at their locations all over the country.

\section{Advice Condition}

Q: What advice do you have for managers who are conducting their own job interviews? A: Interviewers should come up with a list of questions they want to ask for any job they are hiring for. These questions should be based on what types of candidates the manager is looking for and the most important traits of a good employee. If the manager is looking for applicants who won't steal, they need to ask the applicant about situations where they could have stolen or saw someone else steal from work. If customer interaction is important, then the interviewer should ask about instances where the job candidate had to deal with a difficult situation with a customer. This is the best way to predict how the job candidate will actually behave on the job. 
Those same questions should then be used on all the applicants. When judging applicants' answers, the interviewer should also have a scoring rubric and know what makes a good answer and what makes a poor answer.

Q: What are some benefits and drawbacks of this type of structured interview?

A: Well, the obvious answer is that the interviewer has less freedom to improvise on the spot in a structured interview. They have to stick to the script when it comes to choosing what questions to ask. And when it comes to making judgments, they have to follow the rubric to figure out how good the response is. Not all managers will like that. A lot of managers prefer a traditional interviewing method, where they can ask questions as they come to mind or questions that they think best fit a particular situation. But the upside is research has shown that the structured interview is much better at assessing a job candidate in terms of predicting his or her future performance. So, if you use this type of interview, you will likely end up hiring better employees in the future. 


\author{
Appendix B \\ Background Information Scripts for Study 1
}

Impoverished Condition

Q: Tell me a little about yourself and what you do.

A: My name is \{consultant name $\}$, I'm an industrial organizational psychologist. I have a $\mathrm{PhD}$ from \{ alma mater \}, and I'm a consultant at \{company name $\}$. My job is to design and maintain tests and assessments that are used for personnel selection. This includes making sure that these tools are fair, making them interesting for the people who take them, and making sure they help organizations hire the best person for the job.

\title{
Enriched Condition
}

Q: Tell me a little about yourself and what you do.

A: My name is \{consultant name \}, I'm an industrial organizational psychologist. I have a $\mathrm{PhD}$ from \{alma mater , and I'm a consultant at \{company name $\}$. My job is to design and maintain tests and assessments that are used for personnel selection. This includes making sure that these tools are fair, making them interesting for the people who take them, and making sure they help organizations hire the best person for the job.

Q: What got you into your current profession?

A: I got into my current profession because I have always been fascinated by psychology and how psychologists measure things we can't see like personality and intelligence. I also wanted something that would incorporate my interest in statistics.

Q: How would you describe your day-to-day on the job?

A: My day-to-day consists of quite a bit of computer programming and analyzing data to design the scoring for new tests and to make sure that things are functioning as they should. I also get to hear feedback on new assessments and tests from the organizations that use them, and brainstorm with my colleagues on how to design the best possible tools for organizations. 


\section{Appendix C}

Story vs. Advice Scripts for Study 2

Message Topic

Story Condition

Advice Condition

Instructions \& Background

Imagine that you are at an HR conference and a presenter is discussing structured job interviews for interviewing job applicants. Specifically, interviewers who conduct structured job interviews ask the same set of predetermined questions to the applicants and score the results based on a standard benchmark.

In the next sections, you will read the transcript of the presenter and you will be asked some questions about it afterwards.

Introduction of presenter

What is the business problem?

How organizations typically conduct interviews?
As an industrial and organizational psychologist, I often consult with companies about their hiring practices. Last summer, a large financial company contacted our firm about helping them with their interviewing process.

For the past few years, they have experienced a lot of employee turnover and low performance. They were interested in how we can help them reduce turnover and improve employee productivity.

First, I sat down with the HR department and asked them to describe their current hiring process. I met with a few managers over coffee and asked if they could describe their interview process, and no one could give me a good answer. They all just said they interviewed the applicants how they see fit.
As an industrial and organizational psychologist, I often consult with companies about their hiring practices.

I help firms address issues with employee turnover and low performance. I help them reduce turnover and improve employee productivity.

When managers are asked about their current hiring process, they typically don't have good answers about their procedures. They usually interview applicants how they see fit. 
Ask the jobholders about job relevant traits

Develop interview questions ahead of time

Determine the answer and establish scoring guide

Ask the same questions to every applicant and use the predetermined scoring guide.

\section{Statistical information} manipulation (when applicable)
So, I decided to start fixing the problem there by helping them conduct structured interviews. I sat down with my team and asked the management about the most important characteristics they want in an applicant, like integrity, conscientiousness, and so on.

Next, we developed interview questions that asked the applicant to describe their past behaviors that are relevant to those characteristics.

This took a few weeks but eventually, we had a list of questions. We also worked together to determine what makes a good answer for each question, and how to rate the applicant's responses.

I instructed the hiring managers that they should only ask the questions from the list we developed and use the numerical scoring guide to evaluate the applicants. They ended up using this system for two of their locations in the country.

$\underline{\text { Scientific research has found that structured job interviews }}$ correlate $r=0.57$ with future job performance whereas the unstructured job interview correlate $r=0.20$ with future job performance. Correlation "r" represents the strength of the relationship between two variables. When $r=0$, it means there is no relationship between the two variables. When $r=1$, it means there is a perfect relationship between two variables (e.g., interview score and job performance).
To fix the problem, you should conduct structured interviews. You should sit down with your team to figure out what the most important characteristics you want in an applicant, like integrity, conscientiousness, and so on.

You should also develop interview questions that asks the applicants to describe their past behaviors that are relevant to those characteristics.

Once you have a list of questions, you should also determine what makes a good answer for each question, and how to rate the applicant's responses.

As the hiring manager, you should only ask the questions from the list you developed and use the numerical scoring guide to evaluate the applicants.

Scientific research has found that structured job interviews correlate $r=0.57$ with future job performance whereas the unstructured job interview correlate $r=0.20$ with future job performance. Correlation " $r$ " represents the strength of the relationship between two variables. When $r=0$, it means there is no relationship between the two variables. When $r=1$, it means there is a perfect relationship between two variables (e.g., interview score and job performance). 
By the summer's end, they reported a significant drop-off in absenteeism and an increase in performance. They were so thrilled with our work that we are now contracted to implement structured interviews at their locations all over the country.
I hope you find this advice helpful to implement structured interviews at your organization in order to reduce absenteeism and increase performance.

Note. Statistical information passages (underlined) are only presented to half of the participants who received the treatment. 